\title{
Correction to: The role of the WNT signaling pathway in the maxillary sinus squamous cell carcinoma
}

\author{
Bakiye Goker Bagca ${ }^{1}\left(\right.$ D Cigir Biray Avci $^{2} \cdot$ Baha Sezgin $^{3} \cdot$ Ali Veral $^{4} \cdot$ Sercan Gode ${ }^{3} \cdot$ Halil Bulent Karci $^{3}$
}

Published online: 2 March 2022

○) Springer Science+Business Media, LLC, part of Springer Nature 2022

Correction to: Medical Oncology (2022) 39:42

https://doi.org/10.1007/s12032-021-01640-5

The original version of this article unfortunately contained a mistake in the funding information. The fund number should read as "18-TIP-004". The correct funding section is given below.

Funding This study was supported by Ege University Research Foundation (Project No. 18-TIP-004).

Publisher's Note Springer Nature remains neutral with regard to jurisdictional claims in published maps and institutional affiliations.

The original article can be found online at https://doi.org/10.1007/ s12032-021-01640-5.

Bakiye Goker Bagca

bgbagca@adu.edu.tr; goker.bb@gmail.com

1 Faculty of Medicine, Department of Medical Biology, Aydin Adnan Menderes University, Aydin, Turkey

2 Faculty of Medicine, Department of Medical Biology, Ege University, Izmir, Turkey

3 Faculty of Medicine, Department of Otorhinolaryngology, Ege University, Izmir, Turkey

4 Faculty of Medicine, Department of Pathology, Ege University, Izmir, Turkey 